\title{
Occupational HIV risk for health care workers: risk factor and the risk of infection in the course of professional activities
}

This article was published in the following Dove Press journal:

Therapeutics and Clinical Risk Management

14 June 2016

Number of times this article has been viewed

Przemysław Wyżgowski'

Anna Rosiek ${ }^{2}$

Tomasz Grzela'

Krzysztof Leksowski ${ }^{1,2}$

'Department of General Surgery, Military Hospital, ${ }^{2}$ Public Health

Department, Faculty of Health

Sciences, Nicolas Copernicus

University in Toruń, Bydgoszcz, Poland

Video abstract

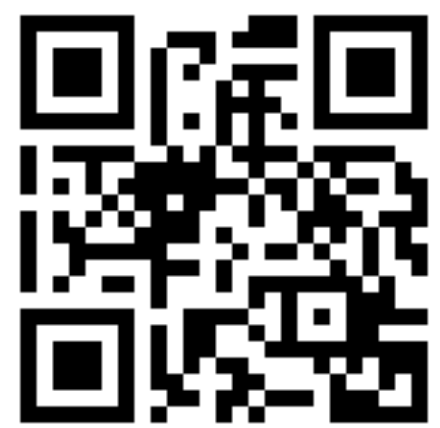

Point your SmartPhone at the code above. If you have a QR code reader the video abstract will appear. Or use

http://youtu.be/ZfraZG4xKB8

Correspondence: Anna Rosiek Public Health Department, Faculty of Health Sciences, Nicolas Copernicus University in Toruń, Przod Pracy 8/7, 85-843 Bydgoszcz, Poland Email ania.rosiek@wp.pl
Abstract: Virtually created panic among health care workers about pandemic acquired immune deficiency syndrome prompted us to review the scientific literature to investigate the risk of human immunodeficiency virus (HIV) transmission in the daily works of health care workers, especially surgeons and anesthesiologists. In this review, we report worldwide valuations of the number of HIV infections that may occur from unsafe daily work in health care. We also present how to minimize the risk of infection by taking precautions and how to utilize postexposure prophylaxis in accordance with the latest reports of the Centers for Disease Control and Prevention. HIV-infected patients will be aging, and most of them will become the candidates for procedures such as major vascular reconstruction and artery bypass grafting, where the risks of blood contact and staff injury are high. For these reasons, all health care workers need to know how to prevent, and fight following the accidental exposure to HIV.

Keywords: HIV infection, risk factor, anesthesiologist, surgeons

\section{Introduction}

Human immunodeficiency virus (HIV) or immunodeficiency virus that leads to acquired immunodeficiency syndrome, called AIDS, is transferred primarily via sex contacts and exposition to infected blood or its ingredients. It is estimated that currently 32.2-38.8 million human beings are HIV-positive globally. ${ }^{1}$ Because of risky behaviors, heterosexuality, development of civilization, and declining boundaries between people, a chance of HIV contagion is a real threat in everyday life. This is particularly true of health care employees including surgeons and anesthetists. Despite a decline in the proportion of newly reported infections of HIV from 3.4 to 2.3 million from 2001 until 2012 per year, which is $\sim 33 \%$, due to medical advances and longer survival of people, approximately one-fourth of the HIV-positive patients will need surgical and/or anesthetic treatment in the future. ${ }^{1,2}$ It should be expected that in the next few years the percentage of HIV patients requiring surgical and anesthetic treatment will be increased further.

\section{HIV: history and epidemiology}

The newly discovered complex disease that was named acquired immunodeficiency syndrome was described in 1981 in a homosexual patient living in the USA, who died of Pneumocystis carinii pneumonia. ${ }^{3}$ In 1983, the pathogen that leads to AIDS, the HIV, was identified and named. Luc Montagnier with his working group (1983) was the first who isolated HIV, at the Pasteur Institute in Garches, near Paris. In 2008, 
Luc Montagnier, together with Françoise Barré-Sinoussi, was awarded The Nobel Prize in Physiology or Medicine for this discovery. Regarding HIV and AIDS, we discuss about a pandemic, which is one of the numerous epidemics of HIV infections in different environments, in different continents at the same time, which differ in the number of patients and the risk of infection on the basis of latitude, type of population, and behaviors.

HIV is a Lentivirus that belongs to a group of retroviruses. There are two variants of this virus, HIV1 and HIV2, which occur primarily in West Africa. ${ }^{4}$ The reverse transcriptase enzyme, in which the retroviruses are equipped, enables them to transcribe their own RNA into DNA and then merge them to host cell genome. The HIV attacks the cells containing antigens CD4 (T-helper lymphocytes and macrophages) on their surface and then destroys them, which leads to immunodeficiency, increased incidence of opportunistic infections, and malignancies. ${ }^{5}$

\section{HIV risk among health care workers}

HIV was isolated from different body fluids, for example, urine, semen, cerebrospinal fluid, blood, tears, amniotic fluid, saliva, breast milk, and vaginal secretions. However, epidemiologists report that HIV infection occurs mainly through sexual contact, contaminated blood, breast milk, semen, and vaginal secretions. ${ }^{6,7}$ It has been proved that blood is the major and the strongest source of infection of not only HIV but also other pathogens and is the major route of transmission in health care employees. ${ }^{8,9}$ On the other hand, infection through semen and vaginal secretions for health care workers seems to be irrelevant, because contact with these fluids is minimal, and even during contact, protective gloves are worn during patient examinations, which are sufficient to prevent infection. Also, infection through cerebrospinal fluid, synovial fluid, and peritoneal or pleural fluid seems to be very unlikely. While searching the global literature, we found one case of HIV infection during puncture and evacuation of bloody fluid from the pleural cavity. ${ }^{10}$ Unfortunately, the risks associated with HIV transmission and other pathogens through the aforementioned body fluids is not certain due to insufficient epidemiological data. The risk of HIV transmission through body fluids such as urine, sputum, feces, vomits, nasal secretions, sweat, and tears is low or even does not exist if they do not contain visible blood. ${ }^{11}$ However, these fluids are also a source of transmission for other pathogens that are dangerous to human health. Human milk can also be a potential risk factor for the infection of blood-borne viruses, including HIV. ${ }^{12,13}$ However, it is not a risk factor for health care workers (except nursing neonate), especially surgeons or anesthesiologists, because of very low or even no exposure to this type of body fluid. Also, saliva of patients infected with the HIV poses no threat to the daily works of surgeons and anesthetists. This was demonstrated by epidemiological data gathered from studies among families living with a HIV-positive member, where HIV was not transmitted to other family members, despite the contamination of open wounds with saliva from the infected family member. ${ }^{8,13-15}$ However, that saliva is a potential source of infection of hepatitis B virus (HBV). ${ }^{11}$

Henderson et $\mathrm{al}^{16}$ conducted an ongoing prospective study for $\sim 6$ years in order to estimate the risk of HIV transmission among health care workers and HIV infection risk associated with the exposure to various risk factors. The median follow-up of health care workers subjected to parenteral exposure to a potential source of HIV infection in the course of their activities was 30.2 months (from 6 to 69 months). In the studied group of 1,344 health care employees, 179 reported percutaneous and 346 mucous membrane exposition to potentially infectious body fluids from a person infected with HIV. After sending an additional questionnaire to 559 employees, it is found that 2,720 reported cutaneous exposure to infected blood with HIV. Also, over 10,000 health care workers reported skin exposure in health care workers to blood from all patients over 12 months. Transmission of HIV was observed in one employee after parenteral exposure to blood from a HIV-positive patient. There was no infection after exposure to HIV-infected blood at the mucosa or skin. Summing up the test results, Henderson et al ${ }^{16}$ estimated that the risk of transmission of HIV infection related to percutaneous exposure to infected blood is $\sim 0.3 \%$ for each exposure. The Center for Disease Control and Prevention, Atlanta, estimates one HIV seroconversion for every 200 contaminated needlesticks. ${ }^{17}$ From the literature, we can also find that the probability of infection of HIV by needle injury is in the range from $0.3 \%$ to $0.03 \%$, which increases with the depth of injuries, volume of inoculated blood, and hollow needle injuries. ${ }^{18}$ The probability of $\mathrm{HBV}$ infection after injury with contaminated needle with blood from HBeAgpositive patient is much higher than in the case of HIV and is $6 \%-30 \%$ versus $0.3 \%{ }^{19,20}$ At least one needle stick injury occurs in $20 \%$ of anesthesiologists during a 3-month work period, in their 30 years of work, and the overall risk of needle injury is $\sim 4.5 \%$. During central vein cannulation, $90 \%$ of the anesthesiologists use gloves, whereas during a peripheral venous cannulation, only $8 \%$ use gloves, which should be $100 \%$ in each case. ${ }^{21}$ On the other hand, the risk of infection associated with the exposure of mucous membranes to the HIV-infected blood is $0.09 \% .{ }^{22,23}$ Hussain et al ${ }^{24}$ 
documented that the risk of accidental injury to staff during surgery is $5.6 \%$ and that the risk is higher in long operations and at the time of laparotomy wound closure. Lowenfels et $\mathrm{al}^{25}$ reported a lower accidental injury rate in operating room staff than Hussain et al, but their figure was based on retrospective estimates.

Marnejon et $\mathrm{al}^{26}$ provide more information regarding the exposure of residents to accidental injury during postgraduate education. In 2000-2014, Marnejon et al recorded 129 needlestick and sharps injuries among the studied group of 924 residents. Approximately $62.7 \%$ of needlestick and sharps injury occurred in the first 6 months during the firstyear postgraduate education. The most vulnerable groups of residents were dental, obstetrics and gynecology, and surgery residents, where exposure to needlestick or sharps injury was $30.6 \%, 28.9 \%$, and $18.5 \%$, respectively. The left index finger $(19.4 \%)$ and the left middle finger $(16.9 \%)$ were the frequently damaged. Approximately $43.4 \%$ of the injuries occurred while using suture needles, $11.6 \%$ while using of scalpels, and 10.1\% while using blood syringes. Fortunately, there was no seroconversion in any of the cases, although 16 patients were infected with hepatitis $\mathrm{C}$ virus (HCV) and one with HBV. ${ }^{26}$

Most of the people with AIDS exhibited high-risk behaviors which led to HIV infection. This also applies to health care workers whose risky behaviors are the cause of $\sim 95 \%$ of HIV infections, and the cause for the remaining 5\% of transmission of HIV infection has not been determined. ${ }^{6}$ In workers of professions other than medical, only $3 \%$ of the employees cannot clearly determine the cause of HIV infection. ${ }^{6}$ The daily routine of health care workers, including surgeons and anesthetists, leads to the fact that they do not treat every patient as a potential HIV-positive. Only when the patient is from the risk group (male homosexuals and bisexuals, intravenous drug abusers, hemophiliacs, and the child of parents who are HIV-positive), they start to take precautions. ${ }^{21}$ Kelen et $\mathrm{al}^{27}$ clearly show that relying on clinical suspicions is insufficient to recognize patients from these groups and that the surgeons who are relying on clinical suspicion will be underestimating the numbers of their patients at risk. ${ }^{27}$

Many surgeons and anesthesiologists think that HIV testing should be performed before surgery or any other invasive procedure. In addition, a negative HIV test in a patient at risk group could reduce vigilance and care of health care workers by the conviction that there is no risk in such patients, who still exhibit high-risk behavior and who in the recent past could have become HIV-positive or is in the serological window. The long incubation time between HIV infection and clinically recognizable sequelae such as AIDS will result in a growing population of asymptomatic HIV carriers. Simultaneously, the cohort of infected patients will be aging and more will become candidates for procedures such as major vascular reconstruction or artery bypass grafting, where the risks of blood contact and staff injury are high. Therefore, it is necessary to realize that every patient can be HIV-positive or can be infected with other blood-borne pathogens; hence, it is very important to apply safety rules in each day for all patients during each medical procedure.

\section{Preventing infections}

What kind of precautions can we take to minimize the risk of transmission of blood-borne pathogens, including HIV? The Center for Disease Control and Prevention from Atlanta clearly presents some general precautions, which are formed to prevent transmission of HIV and other blood-borne pathogens among medical staff while ensuring medical care. ${ }^{6,11}$ As mentioned earlier, it is considered that body fluids (especially blood) of all the patients are potentially contagious for bloodborne pathogens including HIV, HCV, HBV, and others. ${ }^{11}$

The most important precaution is washing hands before and after examining a patient, which is the most often ignored precaution among the medical staff. Also, it is necessary to immediately wash the other parts of the body, if they have been soiled with any body fluid from the patient. Using disposable gloves during every examination of the patient reduces the risk of infection of all pathogens. It also reduces the transmission of any pathogen to the patient from hands of the doctor or the nurse while performing a medical procedure. ${ }^{28,29}$ Global data show that the probability of HIV transmission from a health care worker to a patient is extremely rare and varies depending on the source from $2.4-24$ per million medical procedures. ${ }^{2}$ Wearing double gloves during surgery reduces contamination of the skin by blood, tissue, and other fluids from the patient to the entire surgical team, especially the surgeon. ${ }^{30}$ However, using double gloves is not the general rule. Some surgeons explain that they do not use double gloves because of the discomfort or loss of sensitivity during the surgical procedure. Miles et $\mathrm{al}^{31}$ reported that $26 \%$ of surgeons during an operation removed the second pair of gloves because of discomfort or loss of sensitivity in their hands. While taking blood samples, while changing drips, or in any other situation where there is a possibility of contact with blood or other body fluids, medical personnel should wear protective gloves.

Needlesticks occur particularly when a suture is being placed through tissue directly supported by the opposite hand. This maneuver can be avoided or a thimble or other protective shield can be placed over the distal left index finger 
(in right-handed surgeons), which is the most often penetrated site. ${ }^{31}$ A simple precaution is tying sutures in tissues after cutting needle, which reduces the risk of needlestick injuries with the small costs of more suture usage. Also, surgeon can use staples for bowel anastomosis and skin closure. However, this increases the cost of surgical procedure.

Undoubtedly, wearing protective glasses reduces chance of contamination of the conjunctiva with blood during surgical procedure. Unfortunately, conventional spectacles provide partial but acceptable protection, although they are open on the sides. ${ }^{11,32}$ Brearley and Buist ${ }^{32}$ found that in $25 \%$ of operations in general surgery, there is at least one splash of blood on the protective glasses from the patient. According to their study, of 257 operations, in only three cases, the surgeons were aware of the contamination. ${ }^{32}$ On the other hand, Porteous ${ }^{33}$ points out that the type of the operations have an impact on more or less risk of contamination of the conjunctiva with blood or other tissue from the patient. Hence, joint arthroplasty seems to be a high-risk procedure, with the risk of contamination of the conjunctiva with blood compared with dynamic hip screw insertions ( $84 \%$ versus $51 \%){ }^{33}$

Using impervious gowns by operating room staff reduces the risk of infection. By wearing a protective footwear, the medical personnel prevents feet pollution by bodily fluids. During an operation, the surgeon may use cautery or hand diathermy instead of a scalpel to perform skin incision or cut other tissues in the operating field. Avoiding hand-to-hand passage of sharps, particularly scalpels, is easily done by always placing them in a receiver such as a kidney dish. The most important is the choice of an experienced surgeon to perform the operation. In practice, this may do more than any other precaution to control the spread of the patient's body fluids and tissues and therefore pathogens. All needles and sharps tools after use shall be disposed in a plastic container with thick walls, which has only a small inlet opening at the top. The container should be disposed of when is full at two-thirds capacity.

\section{Postexposure prophylaxis}

The most significant form of prevention of HIV infection among medical staff is to prevent exposure to blood or other body fluids. The term "exposure to HIV" means contact of mucous membrane or damaged skin surface (ie, minor skin injuries and inflammations) or percutaneous injury with potentially infectious body fluids. ${ }^{22}$

Despite precaution, if the surgeon, anesthetist, or any other health care employee comes to exposure of HIV infection, postexposure prophylaxis (PEP), which is to take antiviral drugs as quickly as possible, will be effective. The antiviral drugs should be taken maximum of 72 hours after the exposure and at least for 4 weeks. $^{22,34}$ The purpose of these drugs is to stop the replication of the virus, which is to prevent a carrier of the virus. However, the PEP may not be always effective. ${ }^{26}$ To increase PEP effectiveness in practice, we must apply the proper workflow. In the first step, we should examine the patient toward his or her viremic status and carefully estimate to what they have been exposed to (dirt conjunctivitis, needlestick, or others). Depending on the nature of the inoculum and the patient's viremic status, we can start the pharmacological treatment (usually consisting of three drugs) as soon as possible. The best solution is the ability to consult with an expert on PEP, which selects the appropriate regimen of drugs depending on the type of exposure, medical history, drug interactions, and possible drug resistance. Currently, there are six classes of antiretroviral drugs, but usually in PEP, nucleoside reverse transcriptase inhibitors, integrase inhibitors, protease inhibitors, and non-nucleoside reverse transcriptase inhibitors are used. According to the latest recommendations, the PEP usually begins with the combination of three antiretroviral drugs (or even four if there are indications) and lasts for 4 weeks. ${ }^{35,36}$ The implementation of new therapies in the treatment of AIDS and patients with HIV is much more effective. Combination therapy containing HIV protease inhibitors is often determined as highly effective antiretroviral therapy. All health care workers (patients) receiving a PEP should complete a 4-week treatment. Unfortunately, according to data published in the literature, many health care employees who started PEP with old generation of antiretroviral drugs did not take a full 4-week treatment regimen because of numerous side effects. ${ }^{37-45}$ All the antiretroviral drugs cause side effects, for example, vomiting, rash, abdominal pain, diarrhea, hyperbilirubinemia, jaundice, fever, headaches, liver damage, nephrolithiasis, dizziness, sleep disturbances, respiratory symptoms, and others; therefore, proper selection of antiretroviral drugs according to their toxicity and the ability to easily reverse the side effects is a key in choosing a regimen for PEP. Therefore, a detailed discussion with the person who is going to start prevention and the use of drugs that reduce side effects helps to complete a full 4-week treatment regimen by a person who has been exposed to HIV infection. PEP can be stopped only in a situation where it is proved that the infectious material comes from HIV-negative patient, which is not in "serological window". Another problem is with the pregnant health care workers who are exposed to HIV. According to the guidelines, in this situation, the postexposure procedure is the same as with any other person who has had exposure to the HIV. The decision 
to begin postexposure treatment in pregnancy must be carefully discussed between the woman and the doctor on the potential benefits and side effects for both the mother and the fetus in association with the use of antiretroviral drugs. We already know that we should avoid certain drugs during pregnancy, for example, efavirenz, stavudine, didanosine, and indinavir because they are teratogenic and may cause lactic acidosis or hyperbilirubinemia in newborns. ${ }^{18} \mathrm{~A}$ regimen containing three (or more) antiretroviral drugs is now recommended routinely for all occupational exposures to HIV. Routinely, a regimen consisting of three drugs such as integrase inhibitors with nucleoside reverse transcriptase inhibitors, and a nonnucleoside inhibitor of reverse transcriptase or protease inhibitor is usually preferred. ${ }^{22}$ The recommended PEP regimen is emtricitabine with tenofovir, which can be taken as a single tablet (Truvada) once a day supplemented with raltegravir $400 \mathrm{mg}$ twice daily. ${ }^{22}$ It is also a regimen that can be used in a pregnant woman. Due to the toxicity of tenofovir in patients with kidney disease, the drug may be replaced, for example, with zidovudine, which can be combined with lamivudine in the form of one drug (Combivir).

Health care workers who are exposed to HIV infection must be tested immediately in the direction of viremic status. Further tests are performed at 6 and 12 weeks and 4 months after exposure (duration of follow-up for exposed health care workers has been reduced to 4 months with the availability of the fourth-generation HIV tests - editor's note). Extended observation is recommended for health care employees who are exposed to $\mathrm{HCV}$ infection from a patient who is a carrier of both HIV and HCV. ${ }^{22}$ Each patient receiving PEP must be monitored in the context of toxicity of antiretroviral drugs at baseline and after 2-week therapy. The minimum parameters that should be evaluated during therapy include blood count and kidney and liver function tests. Depending on the detected disorders, the treatment can be modified.

\section{Summary}

The risk of HIV infection is not very high, but every health care worker, especially the surgeon or anesthesiologist, must observe precautions to prevent transmission of HIV in their daily work. Each patient who undergoes any medical procedure should be treated as a potential carrier of HIV. If, despite the precautions, there is needlestick or any other exposure to potentially infectious material by health care personnel, they need to report it immediately to the appropriate staff in the workplace in order to make assessment of the risks of infection as soon as possible and to implement appropriate steps to prevent the progress of HIV infection, including the PEP prevention. Underestimation of the slightest contamination with infectious material in our body may be fatal for our health in the future; hence, it is important to react adequately to possible exposure. Health care workers who are HIV-positive should not perform invasive medical procedures unless they will consult with experts about the possibility of doing such procedures, and each patient will be informed of the fact that the procedure will be performed by a worker who is HIV-positive. ${ }^{29,46}$ Health care workers who are infected with HBV, HCV, HIV, or other pathogens do not have to resign from their job but can try to modify their specialty to continue providing medical services. ${ }^{19}$

\section{Disclosure}

The authors report no conflicts of interest in this work.

\section{References}

1. Global Report 2013 - UNAids report on the global epidemic. Available from: http://www.unaids.org. Accessed November 1, 2015.

2. Prout J, Agarwal B. Anaesthesia and critical care for patients with HIV infection. Continuing Education in Anaesthesia, Critical Care \& Pain. 2005;5:153-156.

3. Gottlieb MS, Schroff R, Schanker HM, et al. Pneumocystis carinii pneumonia and mucosal candidiasis in previously healthy homosexual men: evidence of a new acquired cellular immunodeficiency. $N$ Engl J Med. 1981;305(24):1425-1431.

4. Ibe S, Yokomaku Y, Shiino T, et al. HIV-2 CRF01_AB: first circulating recombinant form of HIV-2. J Acquir Immune Defic Syndr. 2010; 54(3):241-247.

5. Parthasarathy S, Ravishankar M. HIV and anaesthesia. Indian J Anaesth 2010;51(2):91-99.

6. Mason JO. Recommendations for Prevention of HIV Transmission in Health-Care Settings. Centers for Disease Control and Prevention. August 21, 1987;36(suppl no. 2S).

7. Hughes SC. HIV and anaesthesia. Anesthesiol Clin North America. 2004; 22(3):379-404.

8. Centers for Disease Control (CDC). Update: acquired immunodeficiency syndrome and MMWR Morb Mortal Wkly Rep. 1988;37(15): 229-234.

9. Department of Labor, Department of Health and Human Services. Joint advisory notice: protection against occupational exposure to hepatitis B virus (HBV) and human immunodeficiency virus (HIV). US Department of Labor, US Department of Health and Human Services, Washington, DC; Federal Register, 1987.

10. Oskenhendler E, Harzic M, Le Roux JM, Rabian C, Clauvel JP. HIV infection with seroconversion after a superficial needlestick injury to the finger. N Engl J Med. 1986;315(9):582.

11. Centers for Disease Control (CDC). MMWR. Morbidity and mortality weekly report. Perspectives in Disease Prevention and Health Promotion Update: Universal Precautions for Prevention of Transmission of Human Immunodeficiency Virus, Hepatitis B Virus, and Other Bloodborne Pathogens in Health-Care Settings. Centers for Disease Control and Prevention. June 24, 1988;37(24):377-388. Available from: http://www.cdc.gov/mmwr/preview/mmwrhtml/00000039.htm. Accessed May 31, 2016.

12. Lee AK, Ip HM, Wong VC. Mechanisms of maternal-fetal transmission of hepatitis B virus. J Infect Dis. 1978;138(5):668-671.

13. Lifson AR. Do alternate modes for transmission of human immunodeficiency virus exist? A review. JAMA. 1988;259(9):1353-1356.

14. Jason JM, McDougal JS, Dixon G, et al. HTLV-III/LAV antibody and immune status of household contacts and sexual partners of persons with hemophilia. JAMA. 1986;255(2):212-215. 
15. Curran JW, Jaffe HW, Hardy AM, Morgan WM, Selik RM, Dondero TJ. Epidemiology of HIV infection and AIDS in the United States. Science. 1988;239:610-616.

16. Henderson DK, Fahey BJ, Willy M, et al. Risk for occupational transmission of human immunodeficiency virus type 1 (HIV-1) associated with clinical exposures: a prospective evaluation. Ann Intern Med. 1990;113(10):740-746.

17. Guidelines for prevention of transmission of human immunodeficiency virus and hepatitis B virus to health-care and public-safety workers. Centers for Disease Control and Prevention. June 23, 1989;38(6):1-37.

18. Parthasarathy S, Ravishankar M. HIV and Anaesthesia. Indian J Anaesth. 2007;51(2):91-99.

19. Recommendations for preventing transmission of human immunodeficiency virus and hepatitis B virus to patients during exposure-prone invasive procedures. Bull Am Coll Surg. 1991;40(RR08):1-9.

20. Centers for Disease Control (CDC). MMWR. Morbidity and mortality weekly report. Recommendations for protection against viral hepatitis. Centers for Disease Control and Prevention.1985;34:313-324. Available from: https://stacks.cdc.gov/view/cdc/35398. Accessed May 31, 2016.

21. Avidan MS, Jones N, Pozniak AL. The implications of HIV for the anaesthetist and the intensivist. Anaesthesia. 2000;55(4):344-354.

22. Kuhar DT, Henderson DK, Struble KA, et al. Updated U.S. Public Health Service Guidelines for the Management of Occupational Exposures to HIV and Recommendations for Postexposure Prophylaxis. Prepared by the U.S. Public Health Service Working Group. The University of Chicago Press and The Society for Healthcare Epidemiology of America; 2014. Available from: http://www.jstor. org/stable/10.1086/672271. Accessed March 7, 2014.

23. Ippolito G, Puro V, De Carli G. The risk of occupational human immunodeficiency virus infection in health care workers. Italian Multicenter Study. The Italian Study Group on Occupational Risk of HIV infection. Arch Intern Med. 1993;153(12):1451-1458.

24. Hussain SA, Latif AB, Choudhary AA. Risk to surgeons: a survey of accidental injuries during operations. Br J Surg. 1988;75(4):314-316.

25. Lowenfels AB, Wormser GP, Jain R. Frequency of puncture injuries in surgeons and estimated risk of HIV infection. Arch Surg. 1989; 124(11):1284-1286.

26. Marnejon T, Gemmel D, Mulhern K. Patterns of needlestick and sharps injuries among training residents. JAMA Intern Med. 2016;176(2): 251-252.

27. Kelen GD, Fritz S, Qaqish B, et al. Unrecognized human immunodeficiency virus infection in emergency department patients. $N$ Engl Med. 1988;318(25):1645-1650.

28. Bell DM. Human immunodeficiency virus transmission in health care setting: risk and risk reduction. Am J Med. 1991;91(3B):294S-300S.

29. Holmberg SD, Suryaprasad A, Ward JW, Centers for Disease Control (CDC). MMWR. Morbidity and mortality weekly report. Updated CDC Recommendations for the Management of Hepatitis B Virus-Infected Health-Care Providers and Students. Centre for Disease Control and Prevention. July 6, 2012;61(RR03):1-12. Available from: http:// www.cdc.gov $/ \mathrm{mmwr} / \mathrm{preview} / \mathrm{mmwrhtml} / \mathrm{rr} 6103 \mathrm{a} 1$.htm. Accessed November 1, 2015.

30. Matta H, Thompson AM, Rainey JB. Does wearing two pairs of gloves protect operating theatre staff from skin contamination? BMJ. 1988;297(6648):597-598.

Therapeutics and Clinical Risk Management

\section{Publish your work in this journal}

Therapeutics and Clinical Risk Management is an international, peerreviewed journal of clinical therapeutics and risk management, focusing on concise rapid reporting of clinical studies in all therapeutic areas, outcomes, safety, and programs for the effective, safe, and sustained use of medicines. This journal is indexed on PubMed Central, CAS,
31. Miles AJ, Wastell C, Allen-Mersh TG. Protection for the left index finger whilst operating on HIV positive patients. Ann R Coll Surg Engl. 1989;71(4):225.

32. Brearley S, Buist LJ. Blood splashes: an underestimated hazard to surgeons. BMJ. 1989;299(6711):1315.

33. Porteous MJ. Hazards of blood splashes. BMJ. 1990;300(6722):466.

34. Panlilio AL, Cardo DM, Grohskopf LA, Walid Heneine, Ross CS; US Public Health Service. Updated U.S. Public Health Service guidelines for the management of occupational exposures to HIV and recommendations for postexposure prophylaxis. MMWR Recomm Rep. 2005;54(RR09):1-17.

35. Guidelines for the use of antiretroviral agents in HIV-1-infected adults and adolescents. Available from: https://aidsinfo.nih.gov/contentfiles/ lvguidelines/adultandadolescentgl.pdf. Accessed September 17, 2012.

36. Centers for Disease Control (CDC). MMWR. Morbidity and mortality weekly report. U.S. Department of Health and Human Services, Centre for Disease Control and Prevention. Updated U.S. Public Health Service guidelines for the management of occupational exposures to $\mathrm{HBV}, \mathrm{HCV}$, and HIV and recommendations for postexposure prophylaxis. 2001;50 (RR-11):1-42.

37. U.S. Department of Health and Human Services, Centre for Disease Control and Prevention. The National Surveillance System for Healthcare Workers $(\mathrm{NaSH})$ : summary report for blood and body fluid exposures, data collected from participating healthcare facilities (June 1995 through December 2007). Available from: http://www.cdc.gov/nhsn/ PDFs/NaSH/NaSH-Report-6-2011.pdf. Accessed November 1, 2015.

38. Wang SA, Panlilio AL, Doi PA, White AD, Stek M Jr, Saah A. Experience of healthcare workers taking postexposure prophylaxis after occupational HIV exposures: findings of the HIV Postexposure Prophylaxis Registry. Infect Control Hosp Epidemiol. 2000;21(12):780-785.

39. Swotinsky RB, Steger KA, Sulis C, Snyder S, Craven DE. Occupational exposure to HIV: experience at a tertiary care center. J Occup Environ Med. 1998;40(12):1102-1109.

40. Parkin JM, Murphy M, Anderson J, El-Gadi S, Forster G, Pinching AJ. Tolerability and side-effects of post-exposure prophylaxis for HIV infection. Lancet. 2000;355(9205):722-723.

41. Puro V. Post-exposure prophylaxis for HIV infection. Italian Registry of Post-Exposure Prophylaxis. Lancet. 2000;355(9214):1556-1557.

42. Lee LM, Henderson DK. Tolerability of postexposure antiretroviral prophylaxis for occupational exposures to HIV. Drug Saf. 2001;24(8): 587-597.

43. Russi M, Buitrago M, Goulet J, et al. Antiretroviral prophylaxis of health care workers at two urban medical centers. J Occup Environ Med. 2000;42(11):1092-1100.

44. Garb JR. One-year study of occupational human immunodeficiency virus postexposure prophylaxis. J Occup Environ Med. 2002;44(3): 265-270.

45. Grime PR, Ris L, Binns C, Carruthers JR, Williams S. Pan-Thames survey of occupational exposure to HIV and the use of post-exposure prophylaxis in 71 NHS trusts. $J$ Infect. 2001;42(1):27-32.

46. Reitsma AM, Closen ML, Cunningham M, et al. Infected physicians and invasive procedures: safe practices management. Clin Infect Dis. 2005;40(11):1665-1672.

\section{Dovepress}

EMBase, Scopus and the Elsevier Bibliographic databases. The manuscript management system is completely online and includes a very quick and fair peer-review system, which is all easy to use. Visit http://www.dovepress.com/testimonials.php to read real quotes from published authors. 